\title{
Simplifying Complex Insulin Regimens While Preserving Good Glycemic Control in Type 2 Diabetes
}

\author{
Zoltán Taybani (D) · Balázs Bótyik • Mónika Katkó · András Gyimesi • \\ Tamás Várkonyi
}

Received: June 17, 2019 / Published online: July 25, 2019

(C) The Author(s) 2019

\begin{abstract}
Introduction: Type 2 diabetic patients suffering from severe hyperglycemia are often assigned a regimen involving multiple daily injections (MDI) of insulin. If the glucose toxicity resolves, the regimen can potentially be simplified, but there are no guidelines for this, and many patients are left on the MDI regimen. We aimed to prospectively examine the safety and efficacy of switching from MDI to once-daily IDegLira, a fixed-ratio combination of insulin degludec and liraglutide, in relatively well controlled (HbA1c $\leq 7.5 \%)$ subjects with type 2 diabetes on a low total daily insulin dose (TDD).
\end{abstract}

András Gyimesi MD has passed away.

Enhanced Digital Features To view enhanced digital features for this article go to https://doi.org/10.6084/ m9.figshare.8949053.

Z. Taybani ( $₫)$ · B. Bótyik · A. Gyimesi

1st Department of Endocrinology, Dr. Réthy Pál Member Hospital, Békés County Central Hospital, Gyulai street 18, Békéscsaba 5600, Hungary

e-mail: taybanizoltan@gmail.com

M. Katkó

Division of Endocrinology, Department of Internal Medicine, Faculty of Medicine, University of Debrecen, Nagyerdei krt. 98, Debrecen 4032, Hungary

T. Várkonyi

1st Department of Internal Medicine, University of Szeged, Korányi fasor 8, Szeged 6720, Hungary
Methods: 62 adults with type 2 diabetes (baseline age $64.06 \pm 10.24$ years, $\mathrm{HbA}_{1 \mathrm{c}}$ $6.42 \pm 0.68 \%$, BMI $33.53 \pm 6.90 \mathrm{~kg} / \mathrm{m}^{2}$, body weight $\quad 93.81 \pm 19.26 \mathrm{~kg}, \quad$ TDD $43.31 \pm 10.99 \mathrm{IU} /$ day, insulin requirement $0.47 \pm 0.13 \mathrm{IU} / \mathrm{kg}$, duration of diabetes $10.84 \pm 7.50$ years, mean $\pm \mathrm{SD}$ ) treated with MDI \pm metformin were enrolled in our study. Previous insulins were stopped and once-daily IDegLira was started. IDegLira was titrated by the patients to achieve a self-measured prebreakfast blood glucose concentration of $<6 \mathrm{mmol} / \mathrm{L}$.

Results: After a mean follow-up period of 99.2 days, mean $\mathrm{HbA}_{1 \mathrm{c}}$ had decreased by $0.30 \%$ to $6.12 \pm 0.65 \%(p<0.0001)$, body weight had decreased by $3.11 \mathrm{~kg}$ to $90.70 \pm 19.12 \mathrm{~kg}$ $(p<0.0001)$, and BMI had reduced to $32.39 \pm 6.71 \mathrm{~kg} / \mathrm{m}^{2} \quad(p<0.0001) . \quad$ After 3 months of treatment, the mean dose of IDegLira was $20.76 \pm 6.60$ units and the mean insulin requirement had decreased to $0.23 \pm 0.08 \mathrm{IU} / \mathrm{kg}$. IDegLira \pm metformin combination therapy was found to be safe and generally well tolerated. During the month before the baseline visit, 28 patients (45\%) had at least one episode of documented or symptomatic hypoglycemia, while only $6(9.67 \%)$ patients reported a total of 13 documented episodes during the follow-up.

Conclusion: In everyday clinical practice, switching from low-dose MDI to IDegLira in patients with well-controlled type 2 diabetes is 
safe, may result in weight loss and similar or better glycemic control, and substantially reduces the insulin requirement. Simplifying complex treatment regimens decreases treatment burden and may improve adherence to therapy.

Clinical Trial Number: NCT04020445.

Keywords: Deintensification; IDegLira; Overtreatment; Simplification; Type 2 diabetes

\section{INTRODUCTION}

Type 2 diabetic patients suffering from severe hyperglycemia are often assigned a regimen involving multiple daily injections (MDI) of insulin. If the glucose toxicity resolves, the regimen can potentially be simplified, but there are no specific guidelines for this, and many patients are left on the MDI regimen for years, meanwhile a significant proportion of them become overtreated (overtreatment is defined as the application of a treatment even when the potential harm of that treatment exceeds its possible benefits) [1-4].

Patients with type 2 diabetes (T2D) who are treated with hypoglycemic agents too aggressively and have $\mathrm{HbA}_{1 \mathrm{c}}$ values that are permanently lower than the range recommended are considered to be overtreated and overcontrolled. Overtreatment of T2D with hypoglycemic medications is potentially harmful, especially in frail individuals who are elderly or have comorbidities, because it may increase the risk of adverse events such as hypoglycemia and weight gain, it imposes an unnecessary treatment burden on the patient, and it worsens their quality of life. Many recent studies have demonstrated that overtreatment is a common but generally unrecognized problem across the spectrum of patients with T2D [5-7]. Another type of overtreatment is when well-controlled T2D patients are using unnecessarily complex regimens instead of simpler alternatives that would ensure the same glycemic control with a lower treatment burden.

Deintensification is the process of simplifying, reducing, or completely withdrawing medications in order to reduce the risk of polypharmacy and associated adverse events. In spite of the high rates of complex medication, deintensification is relatively uncommon in everyday clinical practice [8-10]. Unfortunately, evidence-based strategies to prevent overtreatment in people with T2D and to simplify MDI regimens are scarce. Moreover, there are many barriers to deintensification at the healthcare professional, general public, and healthcare system levels $[11,12]$.

A first step towards preventing the detrimental medical consequences of and the impaired quality of life caused by overtreatment would be to analyze follow-up trials that are designed to evaluate the outcomes of treatment simplification.

Fixed-ratio combinations (FRCs) consisting of a long-acting basal insulin and a glucagonlike peptide-1 receptor agonist (GLP-1-RA) represent a novel approach to insulin therapy. One of these combinations, IDegLira, comprises a second-generation long-acting basal insulin analog (insulin degludec, 100 units $/ \mathrm{mL}$ ) and the GLP-1-RA liraglutide (3.6 mg/dL). Compared to basal-bolus therapy, IDegLira provides a similar degree of glycemic control but a reduced risk of hypoglycemia, and it has a beneficial effect on body weight [13].

The purpose of the study reported in the present paper was to prospectively examine the safety and efficacy of switching from MDI to once-daily IDegLira in relatively well controlled $\left(\mathrm{HbA}_{1 \mathrm{c}} \leq 7.5 \%\right)$ subjects with $\mathrm{T} 2 \mathrm{D}$ using a low total daily insulin dose (TDD).

\section{METHODS}

\section{Trial Design and Participants}

This was a prospective, single-arm clinical trial of patients with $\mathrm{T} 2 \mathrm{D}$ in a real-world setting. It was conducted at the Diabetes Center of the Békés County Central Hospital-Dr. Réthy Pál Member Hospital (Békéscsaba, Hungary) from January 2016 until 2019.

The T2D patients included in the study were $\geq 18$ years old and had detectable random nonfasting serum C-peptide levels $(\geq 1.1 \mathrm{ng} /$ $\mathrm{mL}$; normal range $1.1-4.1 \mathrm{ng} / \mathrm{mL}$ ) and $\mathrm{HbA}_{1 \mathrm{c}}$ 
$\leq 7.5 \%$, which was treated with MDI (stable daily doses of insulin had been administered for at least for 90 days prior to the baseline visit $[\mathrm{BV}]) \pm$ metformin $(\mathrm{MF})$ at a relatively low TDD. At BV, low TDD was defined as $\mathrm{TDD} \leq 70 \mathrm{IU} /$ day and TDD $\leq 0.6 \mathrm{IU} / \mathrm{kg} /$ day. Clearly overinsulinized patients who had severe or repeated symptomatic hypoglycemia during the month before $\mathrm{BV}$ and had TDD $\leq 70 \mathrm{IU} /$ day and $0.8>$ TDD $>0.6 \mathrm{IU} / \mathrm{kg} /$ day were also admitted to the study. As IDegLira is a relatively costly medicine in Hungary even though it is covered by health insurance, only patients who accepted the expense involved were enrolled in the study.

Exclusion criteria included type 1 diabetes, treatment of T2D with any medication for diabetes other than insulin or metformin during the 90 days before $\mathrm{BV}$, active cancer, anemia (hemoglobin $<100 \mathrm{~g} / \mathrm{L}$ ), and acute or chronic kidney disease with an estimated glomerular filtration rate $<30 \mathrm{~mL} / \mathrm{min} / 1.73 \mathrm{~m}^{2}$.

\section{Procedures}

At BV, previous insulins were stopped and oncedaily IDegLira was started at any time, independent of meals, and repeated at approximately the same time each day. IDegLira was started with 16 units (with each unit containing 1 unit of insulin degludec and $0.036 \mathrm{mg}$ of liraglutide) and patients titrated every 3 days with 2 units in order to achieve a pre-breakfast self-measured blood glucose (SMBG) range of 5-6 mmol/L [14]. The maximum daily dose of IDegLira was 50 units. Metformin was initiated or continued and titrated up by $500 \mathrm{mg}$ weekly to $3000 \mathrm{mg}$ or to the maximal tolerated dose. Patients were asked to test blood glucose daily in a structured manner (one measurement before breakfast and one test before lunch or dinner) and to record SMBG measurements in their diaries.

Patients returned to the Diabetes Center 2 weeks after switching their therapy, at which point their self-titration and adverse events were rechecked (visit 0 ).

Patients were monitored over the course of their routine medical care, and clinical characteristics were assessed at baseline and quarterly (every 3 months) after initiating IDegLira. We present the results obtained at 3 months of IDegLira therapy (i.e., at visit 1 ) in the present paper.

\section{Outcome Measures}

The primary endpoint was the change in $\mathrm{HbA}_{1 \mathrm{c}}$ from baseline to 3 months. Secondary outcomes included changes in body weight, TDD, and incidence of documented (SMBG $<3.9 \mathrm{mmol} /$ L) or symptomatic episodes of hypoglycemia after 3 months of treatment. Severe hypoglycemia requiring external assistance and other clinically meaningful adverse events were also monitored.

\section{Statistical Analysis}

Statistical analysis was performed using GraphPad Prism 6 software (GraphPad Software, San Diego, CA, USA). Data are presented as the mean \pm SD or the median with 25 th and 75 th percentiles (interquartile range, IQR) for continuous variables with normal and non-normal distributions, respectively, and as $n$ (\%) for frequency data. Clinical and demographic variables measured before and after switching therapy were compared using the two-tailed paired $t$ test for normally distributed data and the Wilcoxon signed-rank test for non-normally distributed data. $p$ values $<0.05$ were considered to indicate statistically significant differences.

\section{Ethical Approval and Informed Consent}

Our trial conformed to the recommendations of the Declaration of Helsinki and the International Conference on Harmonisation Good Clinical Practice norms with regard to medical research in humans. The study protocol was approved by the ethical review boards of the institution and the Medical Research Council. All patients provided a written informed consent form before they were enrolled. 


\section{RESULTS}

Between February 2016 and July 2018, 69 T2DM patients meeting the trial's inclusion criteria were switched to IDegLira. Soon after switching, 3 patients ceased the therapy for financial reasons, 1 patient gradually reduced and finally stopped IDegLira due to low SMBG values before visit 1 and remained well controlled on metformin monotherapy, 1 patient discontinued the medication after a few days due to moderate adverse gastrointestinal effects, and 2 patients did not return to the scheduled control. Thus, 62 patients (baseline age $64.06 \pm 10.24$ years, $\mathrm{HbA}_{1 \mathrm{c}} 6.42 \pm 0.68 \%$, BMI $\quad 33.53 \pm 6.90 \mathrm{~kg} / \mathrm{m}^{2}$, body weight $93.81 \pm 19.26 \mathrm{~kg}$, TDD $43.31 \pm 10.99 \mathrm{IU} /$ day, insulin requirement $0.47 \pm 0.13 \mathrm{IU} / \mathrm{kg}$, duration of diabetes $10.84 \pm 7.50$ years, mean \pm SD) attended an assessment 3 months after initiating IDegLira (visit 1) and were included in the analysis (Table 1 ).

At baseline, 49 (79\%) patients were on a basal-bolus regimen using 1 dose of basal insulin and 3 doses of prandial insulin (38 used human and 11 used an analog insulin), and 13 (21\%) patients were treated with two or three doses of human or analog premix insulins (Fig. 1). At BV, 38 (61\%) patients were taking MF (median dose was 1500 [0-2000] mg), the mean number of insulin injections daily was

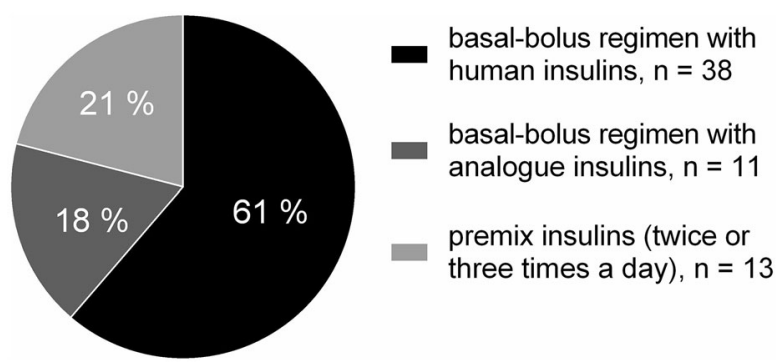

Fig. 1 Proportions of patients using different kinds of insulin regimens at baseline

$3.69 \pm 0.69$, and the mean C-peptide was $4.00 \pm 2.52 \mathrm{ng} / \mathrm{mL}$.

After a mean follow-up of 99.2 days, $\mathrm{HbA}_{1 \mathrm{c}}$, body weight, and BMI had decreased significantly (Figs. 2, 3).

Mean $\mathrm{HbA}_{1 \mathrm{c}}$ decreased by $0.30 \%$ to $6.12 \pm 0.65 \% \quad(p<0.0001)$, body weight decreased by $3.11 \mathrm{~kg}$ to $90.70 \pm 19.12 \mathrm{~kg}$ $(p<0.0001)$, and BMI decreased to $32.39 \pm 6.71 \mathrm{~kg} / \mathrm{m}^{2}(p<0.0001)$.

After 3 months of follow-up, the mean dose of IDegLira was $20.76 \pm 6.60$ units (the mean dose of liraglutide was $0.75 \mathrm{mg}$ ), the median dose of metformin was 2000 [1000-2000] mg, and the mean insulin requirement had decreased to $0.23 \pm 0.08 \mathrm{IU} / \mathrm{kg}$.

IDegLira + metformin combination therapy was found to be safe and generally well tolerated. Transient gastrointestinal adverse events

Table 1 Patient characteristics at baseline and at 3 months of follow-up

\begin{tabular}{lllll}
\hline Characteristic & At baseline & $\begin{array}{l}\text { At 3 months } \\
\text { (visit 1) }\end{array}$ & $\begin{array}{l}\text { Estimated mean difference } \\
(\mathbf{9 5 \%} \text { CI })\end{array}$ & $\boldsymbol{p}$ value* \\
\hline $\mathrm{HbA}_{1 \mathrm{c}}(\%)$ & $6.42(0.68)$ & $6.12(0.65)$ & $-0.30(-0.42$ to -0.18$)$ & $p<0.0001$ \\
Body weight $(\mathrm{kg})$ & $93.81(19.26)$ & $90.70(19.12)$ & $-3.11(-4.04$ to -2.18$)$ & $p<0.0001$ \\
$\mathrm{BMI}\left(\mathrm{kg} / \mathrm{m}^{2}\right)$ & $33.53(6.90)$ & $32.39(6.71)$ & $-1.14(-1.47$ to -0.81$)$ & $p<0.0001$ \\
Total daily insulin dose (units) & $43.31(10.99)$ & $20.76(6.60)$ & $-22.55(24.96-20.14)$ & $p<0.0001$ \\
Insulin requirement (IU/kg) & $0.47(0.13)$ & $0.23(0.08)$ & $-0.24(-0.27$ to -0.21$)$ & $p<0.0001$ \\
Metformin dose (mg/day) & $1500[0-2000]$ & $2000[1000-2000]$ & $\mathrm{NA}$ & $p<0.0001$ \\
\hline
\end{tabular}

Values are the mean (SD) or the median [IQR]

* From the Wilcoxon signed-rank test for metformin dose and the paired $t$ test for other parameters 


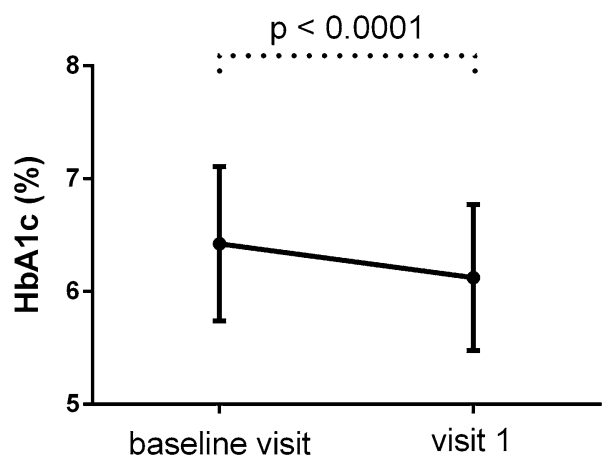

Fig. $2 \mathrm{HbA}_{1 \mathrm{c}}$ (mean $\pm \mathrm{SD}$ ) of the patients at baseline and 3 months later

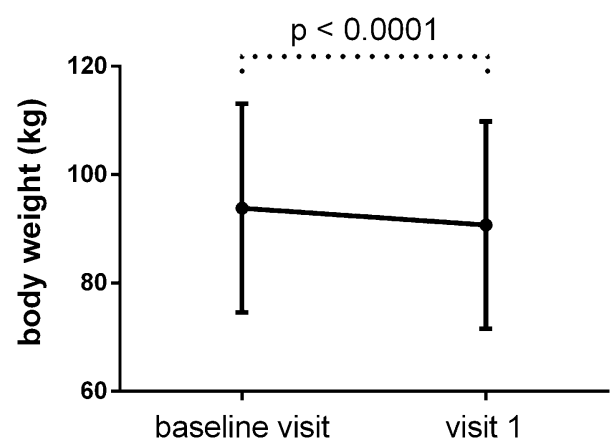

Fig. 3 Body weight (mean $\pm S D$ ) of the patients at baseline and 3 months later

(lack of appetite, nausea, or diarrhea) were reported by 14 patients $(22.5 \%)$, and 1 patient had transient dysthymia. Only one serious adverse event occurred (acute non-ST segment elevation myocardial infarction), which in our opinion was not related to the IDegLira therapy.

During the month before BV, 28 patients (45\%) had at least one episode of documented (self-measured plasma glucose $<3.9 \mathrm{mmol} / \mathrm{L}$ ) or symptomatic hypoglycemia, while only 6 (9.67\%) patients reported a total of 13 documented ( 1 asymptomatic and 12 mild) episodes during the follow-up. Severe hypoglycemia requiring external assistance did not occur (Fig. 4).

The mean daily number of injections changed from 3.69 to 1 , and the patients reported a substantial decrease in the number of blood glucose tests performed each day.

The proportions of the patients who had achieved $\mathrm{HbA}_{1 \mathrm{c}} \leq 7 \%$ and $\mathrm{HbA}_{1 \mathrm{c}} \leq 6.5 \%$ were

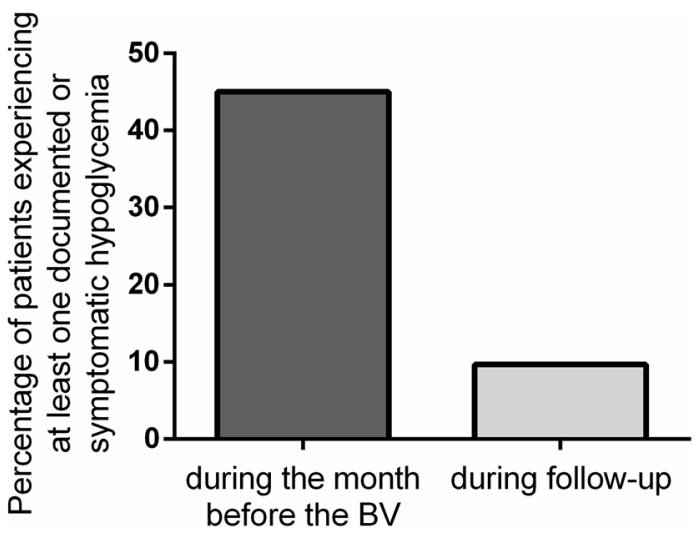

Fig. 4 The percentage of patients experiencing at least one episode of documented (self-measured blood glucose $<3.9 \mathrm{mmol} / \mathrm{L}$ ) or symptomatic hypoglycemia during the month before baseline visit (BV) was $45 \%$, whereas the corresponding percentage at the 3-month follow-up was $9.67 \%$

$92 \%(n=57)$ and 66\% $(n=41)$, respectively (Fig. 5). The proportions of the patients who achieved $\mathrm{HbA}_{1 \mathrm{c}} \leq 7 \%$ and $\mathrm{HbA}_{1 \mathrm{c}} \leq 6.5 \%$ without any weight gain were $79 \%(n=49)$ and 53\% $(n=33)$, respectively. The proportions of the patients who attained $\mathrm{HbA}_{1 \mathrm{c}} \leq 7 \%$ and $\mathrm{HbA}_{1 \mathrm{c}}$ $\leq 6.5 \%$ without hypoglycemia were $82.25 \%$ $(n=51)$ and $56.45 \% \quad(n=35)$, respectively. Finally, the proportions of the patients who realized $\mathrm{HbA}_{1 \mathrm{c}} \leq 7 \%$ and $\mathrm{HbA}_{1 \mathrm{c}} \leq 6.5 \%$ without weight gain and without hypoglycemia were $72.58 \%(n=45)$ and $46.77 \%(n=29)$, respectively.

\section{DISCUSSION}

MDI is recommended as an initial therapy when blood glucose is $\geq 16.7 \mathrm{mmol} / \mathrm{L}, \quad \mathrm{HbA}_{1 \mathrm{c}}$ is $\geq 10 \%$, or if symptoms of hyperglycemia (i.e., polyuria, polydipsia) are present [15]. The main advantage of insulin over other glucose-lowering medications is that it lowers glucose in a dose-dependent manner over a wide range and to almost any glycemic target. The most important barrier to its glucose-lowering potential is the risk of hypoglycemia in many insulin regimens. As the patient's glucose toxicity resolves, the complex regimen introduced initially can potentially be simplified, but there 


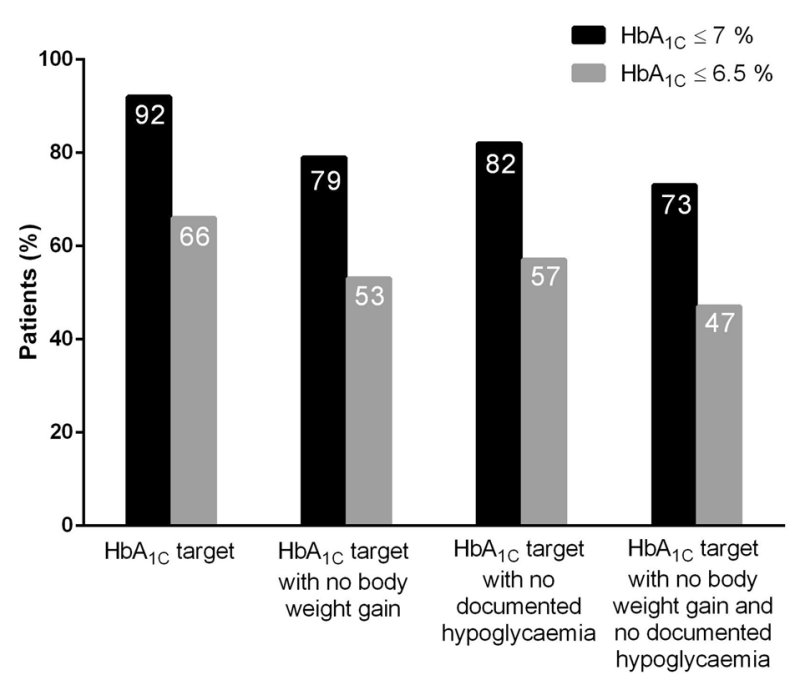

Fig. 5 Proportions of patients who had achieved various glycemic targets at visit 1

are no guidelines for medication deintensification and many patients are overtreated with MDI for years [1-3]. Overtreatment can also occur when T2D patients achieve long-term glycemic control within the target range with an excessively complex insulin regimen. This results in a significant treatment burden and a worse quality of life than achieved with simpler alternatives that permit the same glycemic control.

Clinical practice guidelines have long focused on intensifying therapy to achieve target $\mathrm{HbA}_{1 \mathrm{c}}$ levels soon after diagnosis. Treatment intensification currently involves the stepwise addition of new non-insulin glucose-lowering agents, the initiation of an insulin, or a switch to a more complex insulin regimen. Long-term intensive glucose control can reduce the risk of diabetes-associated microvascular complications, but the type of treatment and the patient's condition play decisive roles in the success of the therapy. The application of an intensive but complex insulin therapy in older patients with several associated comorbidities might lead to perfect HbA1c levels but it may also increase the risks of hypoglycemia and weight gain $[5,16]$. This kind of overtreatment is detrimental to most patients [17]. In line with this, the latest guidelines recommend the deintensification of treatment regimens in older adults [3]. It is also generally accepted that older and younger patients are being overtreated if they are treated too aggressively and their $\mathrm{HbA}_{1 \mathrm{c}}$ values are permanently below their individually defined target ranges. Recent studies suggest that overtreatment is a common and generally unrecognized problem among patients with T2D, but rates of medication deintensification in everyday clinical practice are low, and evidence-based strategies for preventing overtreatment and simplifying therapy are yet to be devised [5-9]. In general, treatment deintensification in T2D involves dosage reduction, the discontinuation of a medication, and the simplification of a complex regimen.

A few studies of a small number of older T2D patients treated with hypoglycemic medications have examined the outcomes of deintensification regimens, but there are no published data on the process of simplifying complex insulin regimens in patients with well-controlled diabetes [12]. The aim of our real-world prospective study was to examine the safety and efficacy of switching from MDI to once-daily IDegLira in relatively well-controlled $\left(\mathrm{HbA}_{1 \mathrm{c}}\right.$ $\leq 7.5 \%$ ) subjects with T2DM using a low TDD. At baseline, most of the patients using complex insulin regimens who were enrolled in our study had optimal glycemic control. Medication simplification was performed in those cases to decrease treatment burden and improve quality of life. However, as some of our patients 
had $\mathrm{HbA}_{1 \mathrm{c}}$ values that were too low, leading to a high risk of hypoglycemia, reducing the frequency of hypoglycemia and achieving appropriate glycemic control were also objectives.

The results of a study of elderly T2D patients $(n=65)$ with one or more episodes of hypoglycemia detected with continuous glucose monitoring (CGM) showed that switching MDI to a single dose of basal insulin (glargine U100) can decrease the risk of hypoglycemia and disease-related distress without compromising glycemic control [11]. In our study, instead of a single long-acting basal insulin, we used IDegLira (a fixed-ratio combination of a long-acting basal insulin and a GLP-1 RA) for medication deintensification because it has been demonstrated that IDegLira produces a significantly greater improvement in overall glycemic control than a basal insulin (due to the fasting and prandial effects of liraglutide) as well as a significantly reduced frequency of hypoglycemia and a more favorable effect on body weight $[18,19]$. Compared to high-dose monotherapies of the two components, we use lower doses of both degludec and liraglutide in the fixed-ratio combinations, which can result in lower risk of adverse effects.

Other works in the literature also encouraged us to use IDegLira to simplify MDI. For instance, the DUAL VII trial demonstrated that IDegLira exerts comparable glycemic effects to MDI on patients with uncontrolled T2DM who are on glargine U100 plus metformin. That trial showed that IDegLira provided lower hypoglycemia rate and weight loss versus weight gain compared to MDI treatment. In addition, the cardiovascular outcome trials LEADER and DEVOTE confirmed the cardiovascular benefits and safety of liraglutide and degludec $[13,20,21]$.

As C-peptide is a widely used measure of pancreatic beta-cell function, we only included patients with detectable levels of this marker in our study. C-peptide is produced in equimolar amounts to endogenous insulin but is excreted at a more consistent rate over a longer period [22].

One of the descriptive parameters analyzed in our study was TDD. The average daily insulin production of healthy men is about $0.7-0.8 \mathrm{IU} /$ kg. Mean TDD in T2DM can vary considerably with the level of insulin resistance and beta-cell function, but Caucasian patients treated with MDI regimens usually have TDDs between 0.9 and 1.4 unit/kg $[13,23,24]$. We supposed that a normal or near-normal $\mathrm{HbA}_{1 \mathrm{c}}$ achieved with a low TDD is associated with some degree of preserved endogenous insulin secretion. We defined a low insulin requirement as an average TDD $\leq 0.6 \mathrm{IU} / \mathrm{kg}$ of body weight, and used this definition together with the C-peptide level to identify potential candidates for our study. Despite the low baseline TDD, the combined application of liraglutide and degludec resulted in a further reduction in TDD and maintenance of an excellent glycemic control.

There are two main explanations for the insulin-sparing effects of liraglutide. On the one hand, liraglutide has a strong glucose-lowering effect deriving from the glucose-dependent enhancement of insulin secretion and the inhibition of glucagon secretion. On the other hand, substantial weight loss is associated with liraglutide treatment, leading to a lower insulin requirement. The safety of our patients was ensured by the study design, as the maximum daily dose of IDegLira was 50 units, and we only enrolled patients with TDD $\leq 70$ units/day at $\mathrm{BV}$ in order to recover from the effects of the previous complex regimen. The therapeutic success of deintensification was observed in other parameters aside from the halved mean insulin requirement and the mean loss of $3 \mathrm{~kg}$ in body weight. Although the baseline glycemic control was acceptable, there was a further reduction in mean $\mathrm{HbA1c}$ and the hypoglycemia risk had decreased substantially at the 3-month follow-up visit. The benefits of deintensification are emphasized by the fact that, at the follow-up visit, $92 \%$ of our patients had $\mathrm{HbA}_{1 \mathrm{c}} \leq 7 \%$, and $72 \%$ had reached that target without weight gain or hypoglycemia.

According to our observations, IDegLira + metformin combination therapy is safe and generally well tolerated. Transient nonserious gastrointestinal adverse events (lack of appetite, nausea, or diarrhea) were reported by 14 patients $(22.5 \%)$, and 1 patient had transient dysthymia. The incidence, severity, and transient nature of these digestive symptoms were 
similar to those reported in another study of T2DM patients on IDegLira [13]. In our study, only one serious adverse event occurred during the follow-up period (acute non-ST segment elevation myocardial infarction), which in our opinion was not related to the IDegLira therapy.

One of our aims was to describe the characteristics of well-controlled T2D patients who are treated with MDI but are eligible for medication simplification, and we wished to demonstrate the feasibility of switching MDI to IDegLira in those patients in everyday clinical practice. The results of our study demonstrated that complex insulin regimens can be simplified in adult T2D patients who have $\mathrm{HbA}_{1 \mathrm{c}} \leq 7.5 \%$, are being treated with low-dose (TDD $\leq 0.6 \mathrm{IU} / \mathrm{kg}$ and $\mathrm{TDD} \leq 70 \mathrm{IU} /$ day) MDI, and have a detectable $(\geq 1.1 \mathrm{ng} / \mathrm{mL})$ random non-fasting serum C-peptide level, indicating that there is some endogenous insulin secretion. We were looking for well-controlled patients, but we found that some of our enrolled patients were overcontrolled, as they were treated too aggressively and had $\mathrm{HbA}_{1 \mathrm{c}}$ values below the target range, leading to a high risk of hypoglycemia.

According to our results measuring $\mathrm{HbA}_{1 \mathrm{c}}$, C-peptide and calculating the TDD can help clinicians to identify well-controlled but overtreated patients who would benefit from medication deintensification. We showed that it is feasible to switch MDI to IDegLira, as the initially overtreated patients in our study achieved similar or better $\mathrm{HbA}_{1 \mathrm{c}}$ values, had fewer episodes of hypoglycemia, lost weight, and performed only one injection daily with IDegLira upon switching from their previous complex insulin regimens. Our observations support the notion that combined liraglutide-degludec treatment has long-term benefits over MDI therapy. The achievement of the target $\mathrm{HbA}_{1 \mathrm{c}}$ lowers the risk of microvascular complications, and the weight loss observed to occur with IDegLira complements its beneficial effects on insulin sensitivity. Furthermore, the need to inject only once rather than 2-4 times daily and the reduced risk of hypoglycemia when using IDegLira appreciably improves quality of life and adherence to therapy.
Our prospective before-after study performed in a real-world setting does, however, have several limitations. It was a nonrandomized, nonblinded, uncontrolled, single-center study. Besides switching to IDegLira, the titration of metformin also affected the $\mathrm{HbA}_{1 \mathrm{c}}$ efficacy, but we could not estimate the strength of that effect. It is also possible that in the patients who were treated with human insulin, switching to a second-generation analog basal insulin could have resulted in a lower risk of hypoglycemia and better glycemic control. Also, the follow-up period was rather short and the sample size was relatively small, which is why enrollment is ongoing at our site-we wish to confirm our results in a larger group of patients and over a longer follow-up period.

\section{CONCLUSION}

Our preliminary data suggest that in everyday clinical practice, switching well-controlled (or overcontrolled) T2DM patients of different ages from low-dose MDI to IDegLira is safe, leads to similar or better glycemic control, substantially reduces the insulin requirement, and may induce weight loss. It should be noted that this approach may, however, be associated with transient digestive symptoms.

Simplifying complex treatment regimens decreases treatment burden and may improve adherence.

\section{ACKNOWLEDGEMENTS}

The authors thank all of the participants in the study.

Funding. No funding or sponsorship was received for this study or the publication of this article. The rapid service fee was funded by the authors.

Authorship. All named authors meet the International Committee of Medical Journal Editors (ICMJE) criteria for authorship for this article, take responsibility for the integrity of the work as a whole, and have given their 
approval for this version to be published. The authors did not receive any medical writing or editorial assistance during the writing of this article.

Disclosures. Zoltan Taybani, Balázs Bótyik, Mónika Katkó, András Gyimesi, and Tamás Várkonyi have nothing to disclose.

Compliance with Ethics Guidelines. Our trial conformed to the recommendations of the 1964 Declaration of Helsinki as revised in 2013, and the International Council on Harmonisation Good Clinical Practice norms with regard to medical research in humans. The study protocol was approved by the local institutional ethical review board and by the Hungarian National Medical Research Council's ethical review board (approval number: 21657). All patients provided a written informed consent form before they were enrolled.

Data Availability. The datasets generated and/or analyzed during the current study are available from the corresponding author on reasonable request.

Open Access. This article is distributed under the terms of the Creative Commons Attribution-NonCommercial 4.0 International License (http://creativecommons.org/licenses/ by-nc/4.0/), which permits any noncommercial use, distribution, and reproduction in any medium, provided you give appropriate credit to the original author(s) and the source, provide a link to the Creative Commons license, and indicate if changes were made.

\section{REFERENCES}

1. Inzucchi SE, Bergenstal RM, Buse JB, et al. Management of hyperglycemia in type 2 diabetes, 2015: a patient-centered approach: update to a position statement of the American Diabetes Association and the European Association for the Study of Diabetes. Diabetes Care. 2015;38:140-9.

2. Jermendy G, Gaál Z, Gerő L, Hidvégi T, et al. Clinical practice guideline-diagnosis, antihyperglycaemic treatment and care of patients with diabetes in adulthood. Diabetol Hungar. 2017;25(1):3-77.

3. American Diabetes Association. 11. Older adults: standards of medical care in diabetes-2018. Diabetes Care. 2018;41(Suppl. 1):S119-25.

4. Chassin MR, Galvin RW. The urgent need to improve health care quality. Institute of Medicine National Roundtable on Health Care Quality. JAMA. 1998;280(11):1000-5.

5. Lipska KJ, Ross JS, Miao Y, Shah ND, Lee SJ, Steinman MA. Potential overtreatment of diabetes mellitus in older adults with tight glycemic control. JAMA Intern Med. 2015;175(3):356-62.

6. Tseng CL, Soroka O, Maney M, Aron DC, Pogach LM. Assessing potential glycemic overtreatment in persons at hypoglycemic risk. JAMA Intern Med. 2014;174(2):259-68.

7. McAlister FA, Youngson E, Eurich DT. Treated glycosylated hemoglobin levels in individuals with diabetes mellitus vary little by health status: a retrospective cohort study. Medicine (Baltimore). 2016;95(24):e3894.

8. Sussman JB, Kerr EA, Saini SD, et al. Rates of deintensification of blood pressure and glycemic medication treatment based on levels of control and life expectancy in older patients with diabetes mellitus. JAMA Intern Med. 2015;175(12):1942-9.

9. McAlister FA, Youngson E, Eurich DT. Treatment deintensification is uncommon in adults with type 2 diabetes mellitus: a retrospective cohort study. Circ Cardiovasc Qual Outcomes. 2017;10(4):e003514.

10. Maciejewski ML, Mi X, Sussan J, et al. Overtreatment and deintensification of diabetic therapy among Medicare beneficiaries. J Gen Intern Med. 2018;33(1):34-41.

11. Munshi MN, Slyne C, Segal AR, Saul N, Lyons C, Weinger K. Simplification of insulin regimen in older adults and risk of hypoglycemia. JAMA Intern Med. 2016;176(7):1023-5.

12. Abdelhafiz AH, Sinclair AJ. Deintensification of hypoglycaemic medications-use of a systematic review approach to highlight safety concerns in older people with type 2 diabetes. J Diabetes Complications. 2018;32(4):444-50.

13. Billings LK, Doshi A, Gouet D, et al. Efficacy and safety of IDegLira versus basal-bolus insulin therapy in patients with type 2 diabetes uncontrolled on metformin and basal insulin: the DUAL VII 
randomized clinical trial. Diabetes Care. 2018;41(5):1009-16.

14. Gough SC, Jain R, Woo VC. Insulin degludec/liraglutide (IDegLira) for the treatment of type 2 diabetes. Expert Rev Endocrinol Metab. 2016;11(1):7-19.

15. American Diabetes Association. 9. Pharmacologic approaches to glycemic treatment: standards of medical care in diabetes-2019. Diabetes Care. 2019;42(Suppl. 1):S90-102.

16. Thorpe CT, Gellad WF, Good CB, et al. Tight glycemic control and use of hypoglycemic medications in older veterans with type 2 diabetes and comorbid dementia. Diabetes Care. 2015;38(4):588-95.

17. Khunti K, Davies MJ. Clinical inertia versus overtreatment in glycaemic management. Lancet Diabetes Endocrinol. 2018;6(4):266-8. https://doi. org/10.1016/S2213-8587(17)30339-X.

18. Gough SC, Bode B, Woo V, et al. Efficacy and safety of a fixed-ratio combination of insulin degludec and liraglutide (IDegLira) compared with its components given alone: results of a phase 3, open-label, randomised, 26-week, treat-to-target trial in insulin-naive patients with type 2 diabetes. Lancet Diabetes Endocrinol. 2014;2(11):885-93.
19. Gough SC, Bode BW, Woo VC, et al. One-year efficacy and safety of a fixed combination of insulin degludec and liraglutide in patients with type 2 diabetes: results of a 26-week extension to a 26-week main trial. Diabetes Obes Metab. 2015;17(10):965-73.

20. Marso SP, Daniels GH, Brown-Frandsen K, et al. Liraglutide and cardiovascular outcomes in type 2 diabetes. N Engl J Med. 2016;375(4):311-22.

21. Marso SP, McGuire DK, Zinman B, et al. Efficacy and safety of degludec versus glargine in type 2 diabetes. N Engl J Med. 2017;377(8):723-32.

22. Leighton E, Sainsbury CA, Jones GC. A practical review of C-peptide testing in diabetes. Diabetes Ther. 2017;8(3):475-87.

23. Rosenstock J, Ahmann AJ, Colon G, Scism-Bacon J, Jiang H, Martin S. Advancing insulin therapy in type 2 diabetes previously treated with glargine plus oral agents. Diabetes Care. 2008;31(1):20-5.

24. Hollander P, Cooper J, Bregnhøj J, Pedersen CB. A 52-week, multinational, open-label, parallel-group, noninferiority, treat-to-target trial comparing insulin detemir with insulin glargine in a basal-bolus regimen with mealtime insulin aspart in patients with type 2 diabetes. Clin Ther. 2008;30(11): 1976-87. 